\title{
Perancangan Sistem Informasi Pelayanan Klinik Alidza Kota Padang Berbasis Web
}

\author{
Riki Iskandar, Dinul Akhiyar \\ Universitas Indonesia "YPTK" Padang, Indonesia \\ Email: 60rikiiskandar@gmail.com, dinul_akhiyar@ymail.com,
}

\begin{abstract}
Research has been carried out at the Padang City Alidza Clinic, where the problem which is the basis of this writing is the savings and loan data processing information system. Through the process of direct observation of spaciousness we have found the weaknesses of the existing system. Although not as a whole, it is more directed to a specific problem, but is expected to make a meaningful contribution to system users. The author designed a clinical service information system that is able to tackle Alidza Padang Padang clinical problems and can produce information on time and the results of that information can be more accurate. In designing this new system, the programming language PHP, UML and MySQL database are used. With this clinical information system the process of recording service data is more efficient and effective because it uses a computerized system.
\end{abstract}

Keywords: System, Information, Service, Clinic, Alidza

\begin{abstract}
Abstrak
Telah dilakukan penelitian pada Klinik Alidza Kota Padang, dimana permasalahan yang dijadikan dasar dalam penulisan ini yaitu sistem informasi pengolahan data simpan pinjam. Melalui proses observasi langsung kelapangan telah didapat kelemahan-kelemahan sistem yang ada. Walaupun tidak secara keseluruhan namun lebih mengarah pada masalah yang spesifik, namun diharapkan dapat memberikan kontribusi yang berarti kepada pengguna sistem. Penulis merancang sistem informasi pelayanan klinik yang mampu menanggulangi masalah-masalah klinik Alidza Kota Padang dan dapat menghasilkan informasi tepat pada waktunya serta hasil dari informasi tersebut bisa lebih akurat. Dalam merancang sistem baru ini digunakan bahasa pemrograman PHP, UML dan database MySQL, Dengan adanya sistem informasi klinik ini proses pencatatan data-data pelayanan lebih efisien dan efektis karena menggunakan sistem yang terkomputerisasi.
\end{abstract}

Kata kunci: Sistem, Informasi, Pelayanan, Klinik, Alidza

\section{Pendahuluan}

Klinik adalah fasilitas pelayanan kesehatan yang menyelenggarakan pelayanan kesehatan perorangan yang menyediakan pelayanan medis dasar dan spesialistik. Pelayanan kesehatan terhadap masyarakat merupakan bagian terpenting untuk meningkatkan kesadaran, kemauan, dan kemampuan hidup sehat bagi setiap orang agar terwujud derajat kesehatan masyarakat yang optimal.Pengelolaan data secara manual mempunyai banyak kelemahan, selain membutuhkan waktu yang lama, keakuratannya juga kurang dapat diterima karena kemungkinan kesalahan sangat besar. Di dalam kegiatannya klinik Alidza masih menanganinya dengan cara manual, salah satu contohnya dalam hal registrasi yang meningkat.Menurut Sutjiadi (2014:36) menyimpulkan apabila sistem pelayanannya yang masih menggunakan sistem lama atau manual, tentu dapat menghambat proses penanganan penyembuhan penyakit yang diderita pasien. Oleh karena itu pada tugas akhir ini penulis membuat Aplikasi Sistem Klinik Berbasis Web dengan studi kasus di Klinik. Adapun tujuan dari penelitian ini adalah ingin mempercepat proses kerja pada klinik. Klinik Alidza merupakan tempat pelayanan kesehatan yang menyediakan pelayanan medis dasar dan atau spesialistik. Petugas pendaftaran dituntut untuk dapat mencatat data pasien sehingga dapat disajikan informasi yang lengkap dan akurat. Dalam upaya peningkatan kualitas pelayanan pasien yang lebih baik Maka diperlukan sebuah konsep atau sistem yang baik yang akan digunakan, sehingga nantinya dapat terwujud suatu pelayanan kesehatan yang bermutu, efektif dan efisien serta dapat meningkatkan kinerja dari klinik itu sendiri. 


\section{Metode Penelitian}

Kerangka penelitian merupakan konsep atau tahapan-tahapan yang akan dilakukan dalam penelitian. Kerangka penelitian ini dapat dilihat pada gambar 2.1.

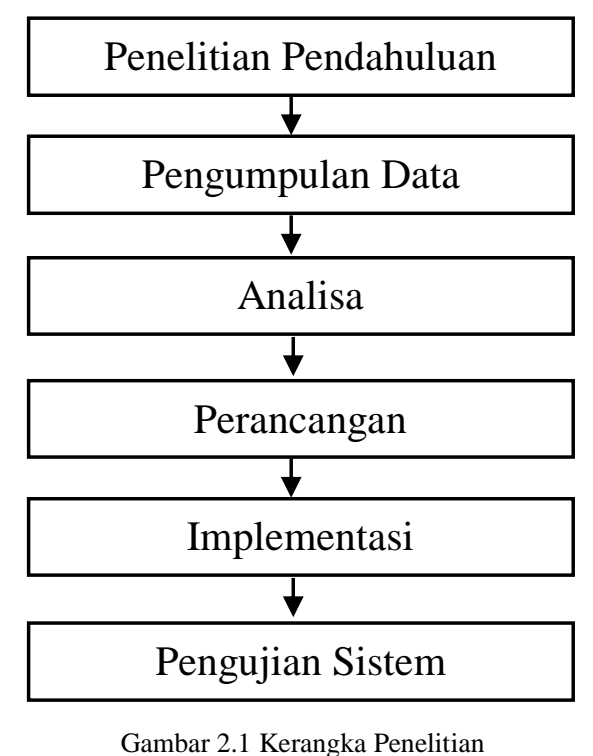

Tahapan Peneletian

Dalam Penelitian ini terdapat beberapa tahapan yang akan dilakukan agar penelitian dapat dilakukan dengan baik. Adapun penelitian tentang tahapan-tahapan penelitian dalam gambar 2.1 Kerangka Penelitian adalah sebagi berikut.

Penelitian Pendahuluan

Penelitian pendahuluan adalah tahapan awal dalam melakukan penelitian, pada tahap ini dilakukan pengumpulan data yang diperlukan dalam penelitian. Tujuan dari penelitan pendahuluan ini adalah untuk mengetahui pemasalahan yang ada pada objek penelitian. Penelitian ini bertujuan untuk membantu Klinik Alidza dalam meningkatkan pelayanan, menyediakan sebuah sistem yang dapat mempermudah karyawan dalam mengolah data pasien, dan untuk membantu Klinik Alidza dalam meningkatkan kualitas pelyanan.

Pengumpulan Data

Pengumpulan data dilakukan dengan mempelajari buku-buku, jurnal, dan tulisan yang berhubungan dengan penelitian ini. Dalam pengumpulan data dilakukan dengan cara mewawancarai pimpinan Klinik Alidza, agar penelitian menhasilkan sebuah data yang optimal.

Analisa

Untuk melakukan penelitian, penulis melakukan analisa terhadap data-data yang telah dikumpulkan serta menganalisa sistem yang akan dijalankan sebagai solusi dari perumusan masalah yang didapat. Yaitu : Pertama Analisis data, Tahap analisa data merupakan tahap yang sangat penting dalam pengembangan sebuah sistem, karena pada tahap inilah yang nantinya akan dilakukan evaluasi kerja. Analisa data dilakukan untuk mendapatkan fakta-fakta berdasarkan metode yang digunakan dalam penelitian, data yang diperoleh dari pimpinan Klinik Alidza akan dianalisa sehingga mendapatkan data yang akurat. Kedua Analisis Proses, Pada tahap analisa proses ini, penulis akan merancang sebuah sistem Klinik. Dimana sistem tersebut diaharapkan dapat menjadi solusi yang tepat untuk unutk membantu pengolahan data pada Klinik Alidza. Dan yang ketiga Analisis system, Pada tahap analisis sistem ini merupakan tahapan yang sangat kritis dan sangat penting, karena kesalahan pada tahapan analisis sistem akan menyebabkan juga kesalahan ditahap selanjutnya. Tahap analisis sistem meruapakan dasar dalam merancang dan merencanakan sistem yang akan dibuat, analisa sistem dilakukan untuk mengetahui apa saja yang dibutuhkan oleh sistem.Analisis sistem ini dilakukan untuk merancang sistem yang meliputi perancangan tampilan user, merancang basisdata untuk sistem 
tersebut agar manajemen file lebih teratur. Dimana sistem yang akan dibuat mengunakan bahasa pemrograman PHP dan database MySQL.

\section{Perancangan}

Tahapan perancangan ini, peneliti mengunakan Unified Modeling Language (UML) sebagai tools dalam menjelaskan alur analisa yang akan dibuat, dimana UML yang digunakan yaitu : Use Case Diagram, Class Diagram, Activity Diagram, Sequence Diagram.

Implementasi

Tahapan implementasi sistem merupakan tahapan memasukkan data-data yang telah diolah dan menerapkan model yang baik sehingga data tersebut siap dioperasikan. Dalam penelitian ini penulis merancang dan membangun sistem informasi berbasis web, untuk mengimplementasikan sistem yang telah dirancang maka diperlukan sebuah alat bantu komputer untuk mengoperasikan sistem tersebut. Untuk mengoperasikan komputer juga diperlukan komponen pendukung seperti hardware, software, dan brainware.

Pengujian Sistem

Proses pengujian terhadap sistem yang dihasilkan untuk mengetahui sistem yang dirancang sudah berjalan dengan benar dan sesuai dengan perancangan yang dilakukan. Adapun pengujian yang dilakukan sebagai berikut : Pertama Pengujian Aplikasi, Pada pengujian aplikasi dilakukan agar sistem yang dibuat sesuai dengan perintah yang akan dijlankan dan bagaimana proses dari sistem ini berjalan. Kedua Pengujian Interface, Dalam pengujian sistem ini nantinya akan dilakukan pengujian interface dimana program yang dibuat akan dilakukan pengujian lapangan. Sistem yang telah dibuat akan diuji oleh beberapa user, apakah disain tampilan program sistem sudah sesuai dengan yang diharapkan dan user friendly atau tidak.

\section{Hasil dan Pembahasan}

Analisa sistem dapat didefinisikan sebagai penguraian dari suatu sistem informasi yang utuh kedalam bagian bagian komponennya dengan maksud untuk mengindentifikasi dan mengevaluasi permasalahan-permasalahan, kesempatan, hambatan, dan kebutuhan- kebutuhan yang diharapkan sehingga dapat diusulkan perbaikan- perbaikannya. Analisa sistem dapat didefinisikan sebagai penguraian dari suatu sistem informasi yang utuh kedalam bagian bagian komponennya dengan maksud untuk mengindentifikasi dan mengevaluasi permasalahan-permasalahan, kesempatan, hambatan, dan kebutuhan- kebutuhan yang diharapkan sehingga dapat diusulkan perbaikanperbaikannya. Dari hasil penelitian yang telah dilakukan baik dengan melakukan survey langsung ke Klinik Alidza Kota Padang maupun tidak langsung, maka dapat diuraikan kerja sistem yang ada Klinik Alidza Kota Padang. Dimana dalam pengolahan data, Klinik Alidza Kota Padang membutuhkan waktu yang lama dan kurang efisien karena masih belum optimalnya penggunaan komputerisasi dan analisa yang dilakukan secara manual.

Evaluasi Sistem Yang Sedang Berjalan

Sistem pada dasarnya masih kurang efektif dan efisien sebagai konsekuensi dari pemrosesan data penerimaan dan pengeluarannya yang masih manual. Meskipun telah menggunakan komputer dalam pengoperasiannya, namun belum mampu menyajikan informasi pembuatan laporan karna masih menggunakan dokumen dalam penyimpanan data.Dari analisa diatas, terdapat beberapa kendala dan permasalahan terhadap sistem yang sedang berjalan diantaranya : Secara garis besar bahwa sistem informasi pengolahan data klinik masih dilakukan secara manual, maka akan membutuhkan waktu yang lama dan bisa terjadi kesalahan dalam pembuatan laporan, Data disimpan dalam bentuk dokumen, apabila dokumen tersebut hilang atau rusak, maka data klinik menjadi tidak jelas, Data yang disimpan secara manual sangat rentan terjadinya pemanipulasian data oleh pihak-pihak yang tidak bertanggung jawab.

Desain Sistem Baru

Perancangan sistem pada suatu organisasi haruslah berjalan sesuai dengan perkembangan organisasi, artinya sistem yang dirancang haruslah lebih baik bila dibandingkan dengan sistem yang lama, baik dalam segi efisiensi maupun dari segi hasil laporan yang dirancang. Desain sistem baru terdiri dari 2 (dua) bagian yaitu Desain Sistem Secara global atau desain sistem secara umum dan Desain Sistem Terinci atau desain sistem secara khusus.

Use Case Diagram 


\section{Copyright@2020 LPPM UPI YPTK}

Use case diagram menjelaskan manfaat dari aplikasi jika dilihat dari sudut pandang orang yang berada diluar sistem (aktor). Diagram ini menunjukkan fungsionalitas suatu sistem atau kelas dan bagaimana sistem berinteraksi dengan dunia luar. Use case diagram dapat digunakan selama proses analisa untuk menangkap requirements atau permintaan terhadap sistem dan untuk memahami bagaimana sistem tersebut harus bekerja. Adapun Use Case Diagram sistem informasi Pelayanan Klinik Alidza pada Kota Padang dapat digambarkan seperti Gambar 3.1.

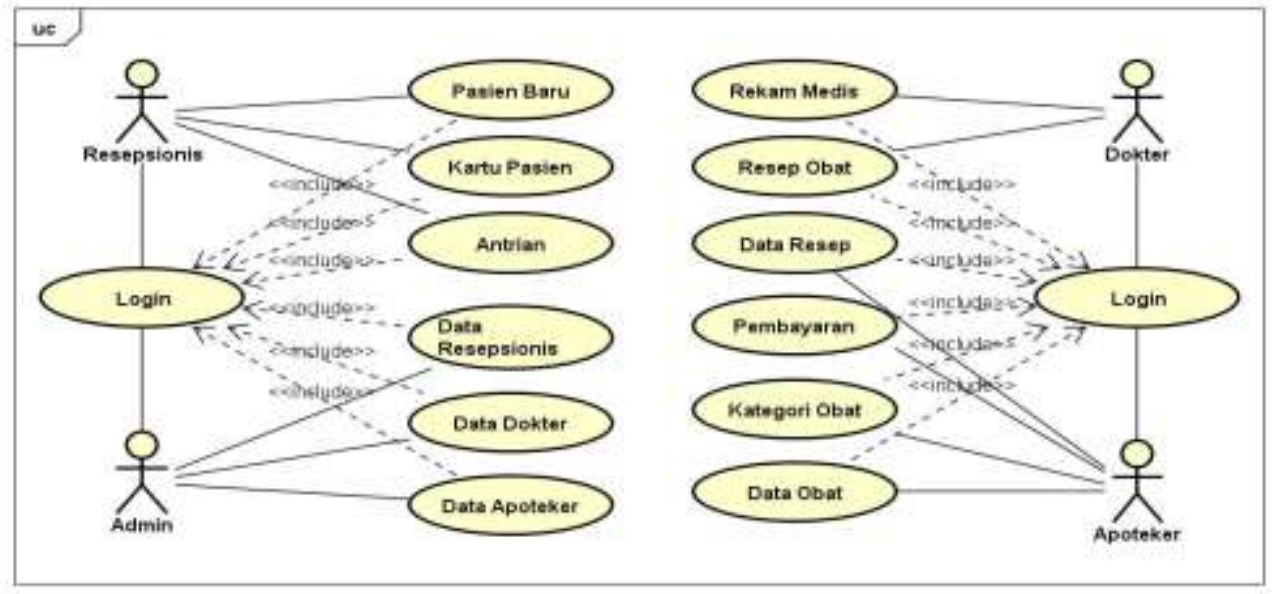

Gambar 3.1 Use Case Diagram

\section{Class Diagram}

Class diagram adalah sebuah spesifikasi yang jika diinstansiasi akan menghasilkan sebuah objek dan merupakan inti dari pengembangan dan desain berorientasi objek. Adapun Class Diagram sistem informasi Pelayanan Klinik Alidza pada Kota Padang dapat digambarkan seperti Gambar 3.2.

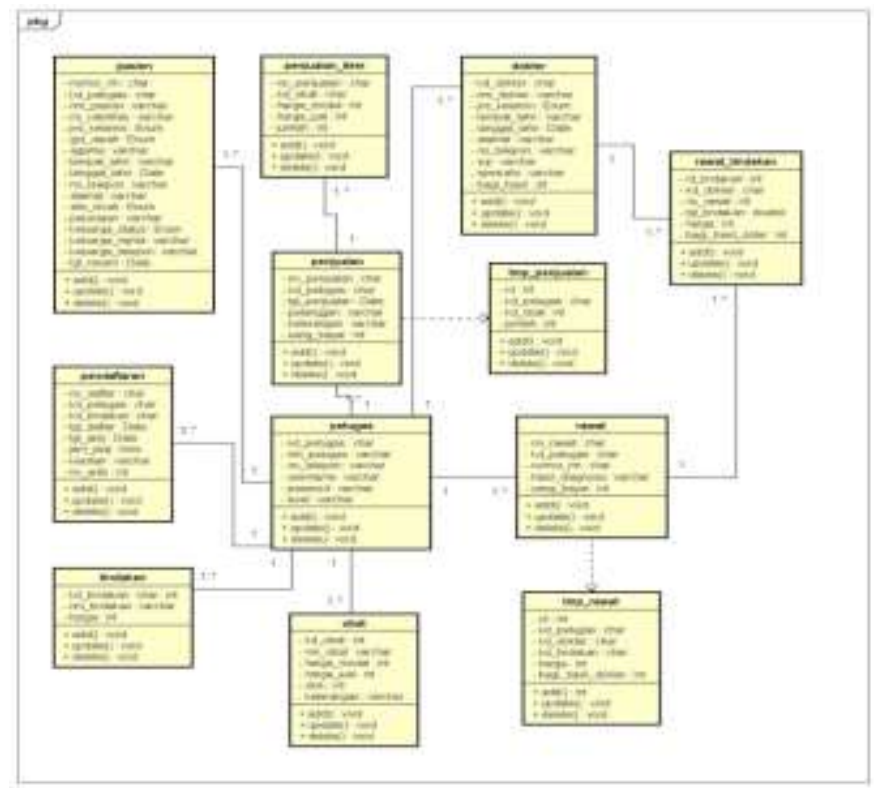

Gambar 3.2. Class Diagram

Pengujian Program

Pada bagian pengujian program ini akan dijelaskan mengenai penggunaan dari aplikasi yang dibuat. Penjelasan aplikasi yang dibuat meliputi tampilan aplikasi, fungsi kontrol dalam aplikasi, serta cara penggunaanya. Pada sub bab akan dijelaskan tentang penggunaan aplikasi per sistem menu, mulai dari tampilan menu utama, fungsi dan cara penggunaannya sampai selesai. 


\section{Tampilan Halaman Utama Petugas Admin}

Tampilan beranda petugas merupakan tampilan awal pada halaman petgas. Pada tampilan menu utama ini terdapat beberapa menu yang dapat diakses oleh petugas yang dapat dilihat pada Gambar 3.3 dibawah ini :

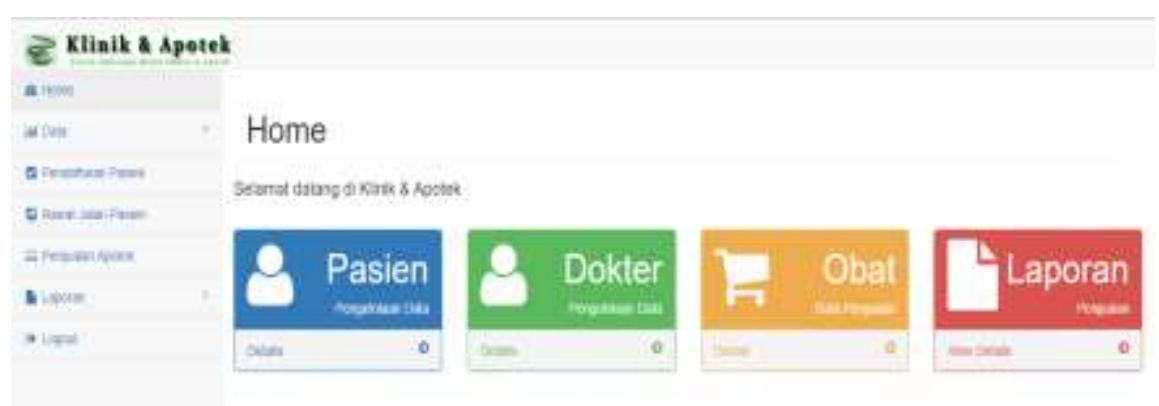

Gambar 3.3 Halaman Utama Petugas Admin

Tampilan Halaman Input Data Pasien

Tampilan halaman data pasien ini memuat pengelolaan data pasien di klinik yang di mulai dai input data pasien, edit data pasien dan hapus pasien. Berikut tampilan halaman data pasien:

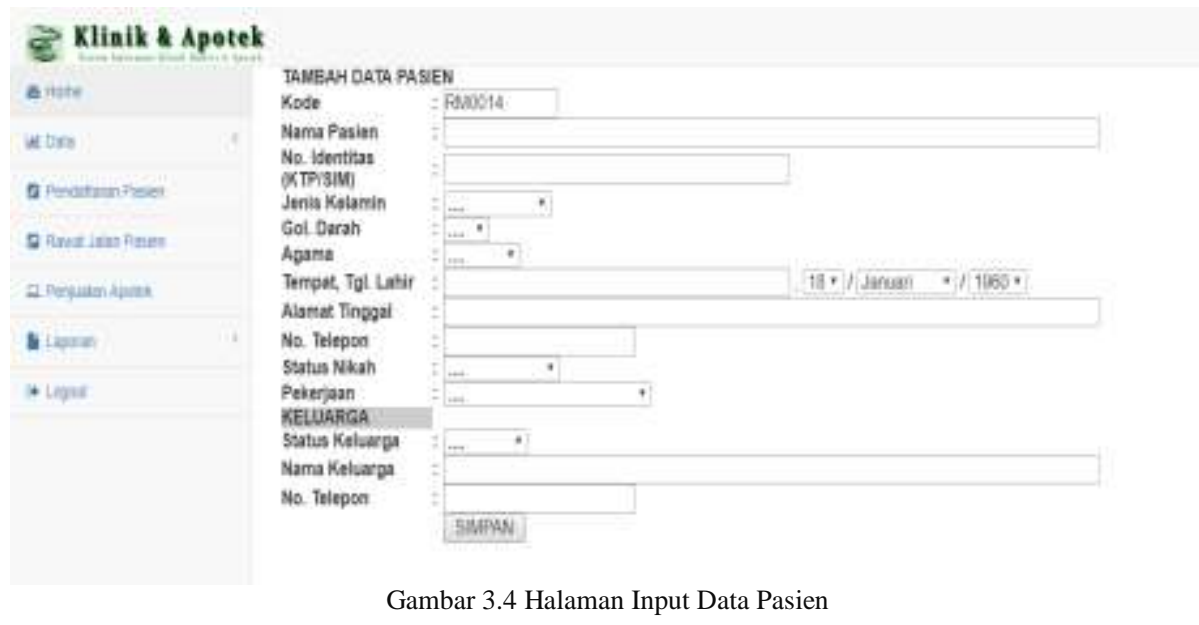

Tampilan Halaman Rawat Pasien

Tampilan halaman rawat Jalan Pasien ini memuat data pasien yang akan diperiksa oleh dokter. Berikut tampilan halaman rawat jalan pasien

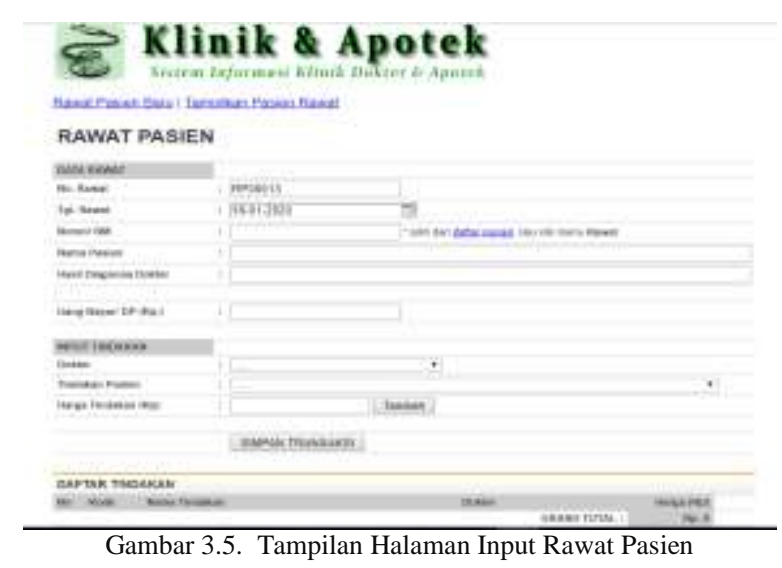

Tampilan Halaman Input Data Obat

Tampilan halaman data obat ini memuat data obat yang ada di klinik. Berikut tampilan halaman data obat. 


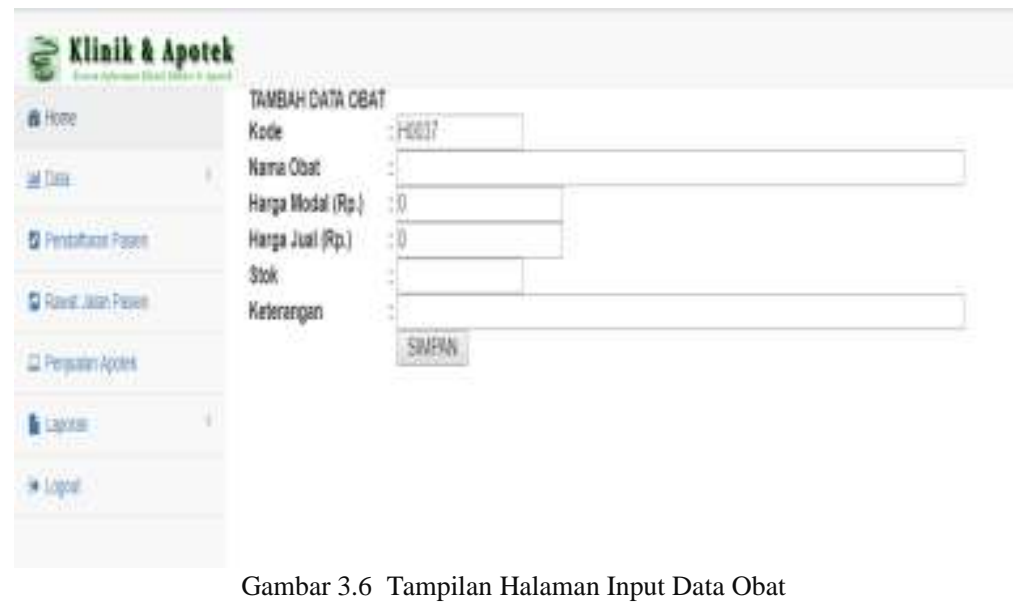

\section{Laporan Data Obat}

Untuk menampilkan dan mencetak Laporan Data Obat maka dapat dilakukan dengan cara klik menu Laporan, pilih Laporan Rawat Pasien lalu klik cetak.

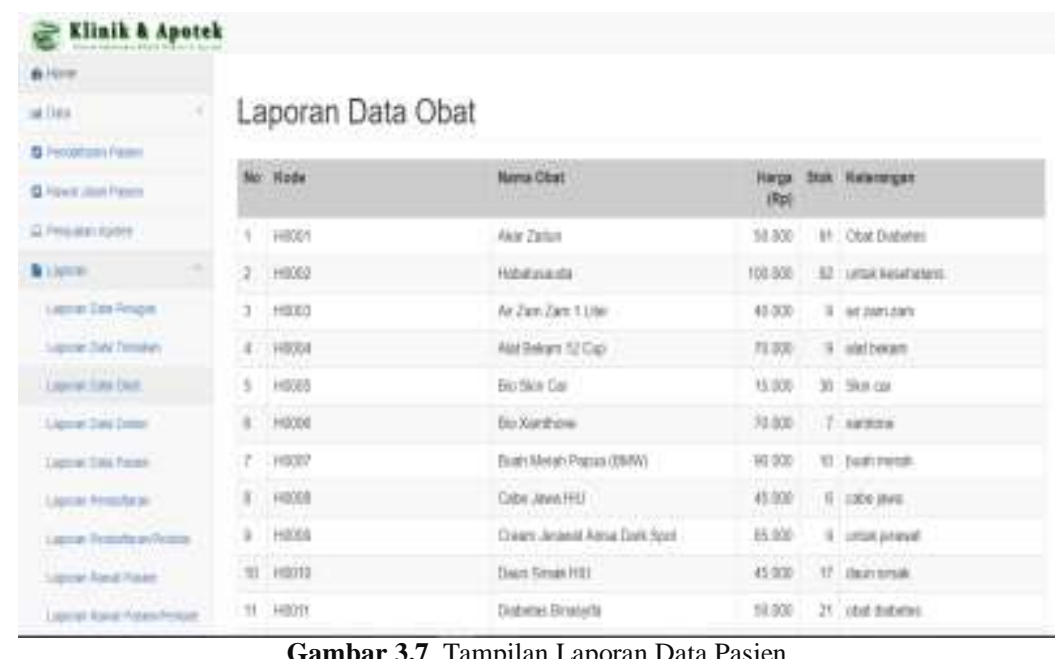

Laporan Data Pasien

Gambar 3.7 Tampilan Laporan Data Pasien

Untuk menampilkan dan mencetak Laporan Data Pasien maka dapat dilakukan dengan cara klik menu Laporan, pilih Laporan Data Pasien lalu klik cetak.

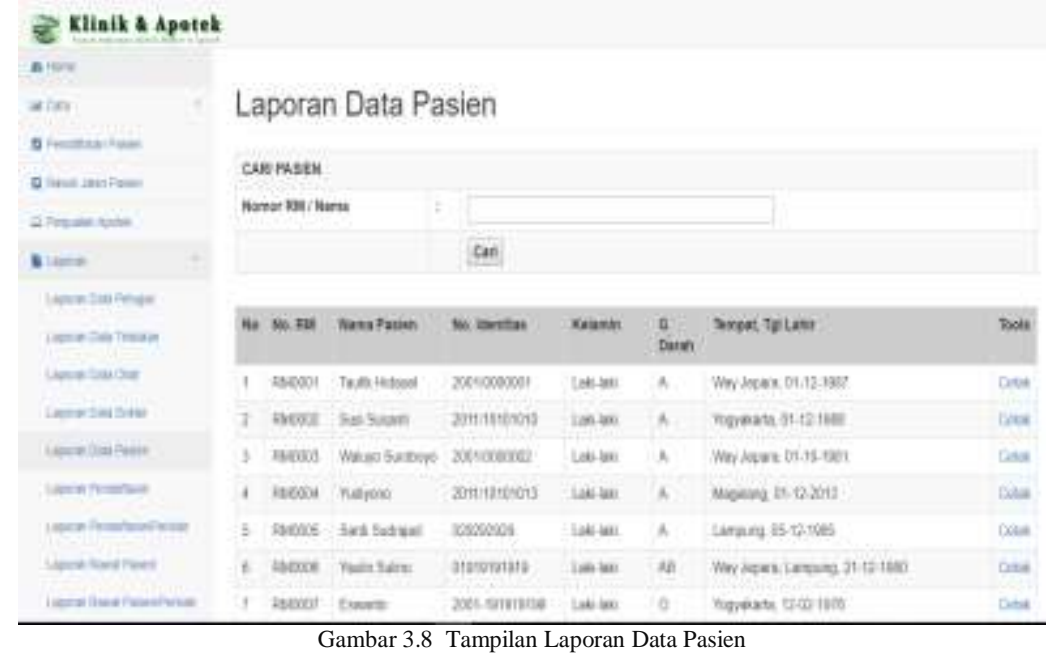

Laporan Rawat Pasien

Untuk menampilkan dan mencetak Laporan Rawat Pasien maka dapat dilakukan dengan cara klik menu Laporan, pilih Laporan Rawat Pasien lalu klik cetak. 
Klinik \& Apotek

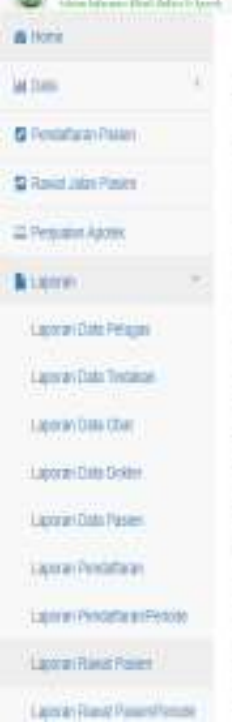

\section{Laporan Rawat Pasien}

\begin{tabular}{|c|c|c|c|c|c|c|c|}
\hline \$o & Mo. Rries & Ty Ravat & $\begin{array}{l}\text { Nemar } \\
\text { By }\end{array}$ & Nara Palen & $\begin{array}{l}\text { Buyar } \\
\text { Fiw }\end{array}$ & Maki Oaseces & Tach \\
\hline 1 & mroxecen & sot.2n & Fance & Tan Hasas & 0 & औitg & Cath \\
\hline 2 & Hatcole & 11.95014 & fuscos & Sxisurat & trape & gg $\mathrm{b}=\mathrm{se}$ & Cast \\
\hline 2 & Aproces & 11-4n.2014 & Funow & Waypo Sundove & 10000 & arteigy & Catal \\
\hline 4 & मFonces & 11012014 & Puevol & Kidipon & 135000 & satigg & ons \\
\hline 5 & Apscost & 25112014 & Functs & SxdStenst & 150000 & Senigy & Cots \\
\hline B & Areccest & 11: & puscoce & Munsimo & 250000 & seklou & Corat \\
\hline$T$ & 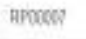 & 34112014 & runcer & Koveng & 30000 & $\sin \alpha$ & Coste \\
\hline 8 & HFonces & $14+113014$ & fance & Untirnes & 150000 & swortribian & Can \\
\hline 9 & Hiprees & 2401.234 & favent & Wad Hanganen & 150000 & & Cank \\
\hline to & APCQOS: & 496e.2.4 & Funote & Sxd Sabjad & 1600000 & $=$ atigg & Catai \\
\hline 11 & APDOOII & 501.2130 & Fanom & Witco Sumapo & ITE000 & & cotai \\
\hline
\end{tabular}

Gambar 3.9 Tampilan Laporan Rawat Pasien

\section{Kesimpulan}

Berdasarkan uraian-uraian dan rancangan sistem yang telah dijelaskan pada bab-bab terdahulu, maka penulis dapat mengambil kesimpulan diantaranya :

1. Dengan adanya sistem informasi klinik ini proses pencatatan data-data pelayanan lebih efisien dan efektis karena menggunakan sistem yang terkomputerisasi.

2. Dengan adanya sistem informasi klinik ini proses pencarian data pasien akan lebih mudah karena telah tersimpan di dalam database.

3. Dengan adanya sistem informasi klinik ini maka pengambilan, pengubahan dan kehilangan data pasien dapat diminimalisir.

\section{Daftar Pustaka}

[1] Ade Hendini. 2016. Pemodelan Uml Sistem Informasi Monitoring Penjualan Dan stok barang ( studi kasus : distro zhezha pontianak). Jurnal Khatulistiwa informatika. 4(2) 1- 11.

[2] Aldian hidayat dkk. 2016. Perancanggan Informasi Penggolahan Nilai BerbasisWeb Pada Sekolah Menengah Atas Negri 5 Bukitinggi Dengan Menggunakan Bahasa Pemograman PHP. Jurnal teknologi. 6(2): 40-44.

[3] A.S, Rosa, Shalahuddin, M. 2018.. Rekayasa Perangkat Lunak edisi revisi.Bandung: Informatika bandung.

[4] Hj.Ria Ratna Ariwati.2016.Riset Akuntansi,Vol III,No 2, ISSN 2086-0.

[5] Monalisa dkk.2017.sistem informasi klinik berbasis web pada klinik umum dan kecantikan dokter dwi anandhita jakarta, , ISSN : $2598-2990$.

[6] Indra Irawan. 2018. Pengembanggan Sistem Informasi Tagihan (Billing System) Passien Rawat Inap Pada Rumah Sakit Umum Daerah Bangkinang Kampar. Riau Jurnal Of Computer Science. 4(2) 2-10.

[7] Kristanto,andri. 2018. Perancangan Sistem Informasi Dan Aplikasinya Edisi Revisi. Yogyakarta : Gava Media.

[8] Madcoms. 2016. Pemograman PHP Dan MySQL Untuk Pemula.Yogyakarta : Andi.

[9] Mardison. 2015. Perancangan dan Implementasi E-commerce Pada Rumah Songket Pusako Minang Pandai Sikek. Jurnal KomTekInfo Fakultas Ilmu Komputer, 2(2) 1-5.

[10] Mardison. 2017. Perancanggan Sistem Informasi Inventory Pada Alinea Mart Berbasis Multi User Dengan Java Neatbean dan MYSQL. Majalah ilmiah. 24(2) 1-8.

[11] Purnama, Chamdam. 2016. Sistem Informasi Manajeman. Mojokerto : Insan Clobal.

[12] Raharjo,Budi. 2015. Belajar Otodidak MSQ (Teknik Pembuatan Penggolahan Databse). Bandung : INFORMATIKA

[13] Sucipto. 2017. Perancangan Active Database System Pada Sistem Informasi Pelayanan Harga Pasar. Jurnal intensif. 1(1) 5-10.

[14] Indra Irawan. 2018. Pengembanggan Sistem Informasi Tagihan (Billing System) Passien Rawat Inap Pada Rumah Sakit Umum Daerah Bangkinang Kampar. Riau Jurnal Of Computer Science. 4(2) 2-10. 